\title{
Serum corticosterone level predicts the magnitude of hippocampal primed burst potentiation and depression in urethane-anesthetized rats
}

\author{
M. CATHERINE BENNETT \\ University of Colorado Health Sciences Center, Denver, Colorado \\ DAVID M. DIAMOND \\ University of Colorado Health Sciences Center, Denver, Colorado \\ and Veterans Administration Medical Center, Denver, Colorado \\ MONIKA FLESHNER \\ University of Colorado Health Sciences Center, Denver, Colorado \\ and \\ GREG M. ROSE \\ University of Colorado Health Sciences Center, Denver, Colorado \\ and Veterans Administration Medical Center, Denver, Colorado
}

\begin{abstract}
Electrical stimulation of the hippocampal commissure with a pattern of pulses that mimics specific aspects of hippocampal physiological activity results in a long-lasting enhancement of the CA1 evoked response. We refer to this pattern-dependent increase in response as primed burst (PB) potentiation (Diamond, Dunwiddie, \& Rose, 1988; Rose \& Dunwiddie, 1986). The primary finding of the present study is that, in the urethane-anesthetized rat, there is a negative linear correlation between the magnitude of PB potentiation and elevated levels of serum corticosterone $(r=-.76, p<.001)$. In contrast, there was no significant relationship between the magnitude of posttetanic potentiation (PTP) and the level of serum corticosterone $(r=.13, p>.1)$. In addition, we observed a novel form of long-term depression of the population spike amplitude (PB depression) in recordings from 4 animals that had very high levels ( $>60 / \mu \mathrm{g} / \mathrm{dl}$ ) of corticosterone. The magnitudes of PTP were not different across groups that developed PB potentiation $(n=9)$, no change in response $(n=7)$, or PB depression $(n=4)$. These findings suggest that corticosterone exerts a concentration-dependent inhibitory influence on long-term, but not shortterm, hippocampal plasticity in the urethane-anesthetized rat. The present findings complement previous work indicating that stress-related adrenal hormones, and corticosterone in particular, can modulate behavioral learning and hippocampal plasticity.
\end{abstract}

Adrenal-related hormones are potent modulators of both learning (Bennett, Liang, \& McGaugh, 1985; Bohus, 1973; Borrell, de Kloet, Versteeg, \& Bohus, 1983; Liang, Bennett, \& McGaugh, 1985; McGaugh, 1989) and brain plasticity (Diamond, Bennett, Engstrom, Fleshner, \& Rose, 1989; Dubrovsky, Liquornik, Noble, \& Gijsbers,

\footnotetext{
This work was supported by grants from the Veterans Administration Medical Research Service and NSF (BNS 9008901) to G. M. Rose and grants from the Veterans Administration Medical Research Service and the Office of Naval Research (ONR NOO014-91-J-1753) to D. M. Diamond. We wish to thank Karen Stevens for assistance with the statistical analyses. M. C. Bennett, D. M. Diamond, and G. M. Rose are in the Department of Pharmacology at the University of Colorado Health Sciences Center; G. M. Rose is also affiliated with the Neurosciences Training Program at the Health Sciences Center, and M. Fleshner is in the Department of Microbiology/Immunology. Address correspondence to G. M. Rose, Medical Research (151), VA Medical Center, 1055 Clermont St., Denver, CO 80220.
}

1987; Gold, Delanoy, \& Merrin, 1984). Corticosterone, the primary glucocorticoid in rodents, is released from the adrenal cortex during stress and can modulate learning (Archer, Ogren, Fuxe, Agnati, \& Eneroth, 1981; Bohus, 1973; Bohus \& de Kloet, 1981; Bohus, Grubits, Kovacs, \& Lissak, 1970) and neural activity (Joels \& de Kloet, 1989; Kerr, Campbell, Hao, \& Landfield, 1989; Pfaff, Silva, \& Weiss, 1971; Reiheld, Teyler, \& Vardaris, 1984). The highest density of corticosterone receptors in the nervous system is found in the hippocampus (Magariños, Ferrini, \& De Nicola, 1989; Reul \& de Kloet, 1985), a structure that serves a critical role in memory formation (Squire, 1986; Zola-Morgan, Squire, \& Amaral, 1986). Collectively, these lines of research suggest that the corticosterone modulation of hippocampal activity underlies some aspects of the effects of stress on learning and memory. 
Hippocampal long-term potentiation (LTP) is a welldescribed physiological model of memory, in which a long-lasting enhancement in synaptic efficacy occurs in response to high-frequency electrical stimulation (Lynch, Muller, Seubert, \& Larson, 1988; Teyler \& DiScenna, 1987). LTP has characteristics in common with memory, such as its rapid induction and long duration. Moreover, recent work has shown that electrical stimulation patterned to mimic aspects of hippocampal physiology is maximally effective at inducing LTP (Diamond, Dunwiddie, \& Rose, 1988; Greenstein, Pavlides, \& Winson, 1988; Larson \& Lynch, 1986; Larson, Wong, \& Lynch, 1986; Pavlides, Greenstein, Grudman, \& Winson, 1988; Rose \& Dunwiddie, 1986). We refer to this low threshold form of LTP as primed burst (PB) potentiation (Diamond et al., 1988; Rose \& Dunwiddie, 1986).

Previous studies have demonstrated that stress inhibits LTP (Foy, Stanton, Levine, \& Thompson, 1987; Shors, Seib, Levine, \& Thompson, 1989) and PB potentiation (Diamond, Bennett, Stevens, Wilson, \& Rose, 1990), and that adrenalectomy enhances the induction of $\mathrm{PB}$ potentiation (Diamond et al., 1989). These findings suggest that adrenal-related hormones exert an inhibitory influence on hippocampal plasticity. In the present study, we have therefore characterized the relationship between the magnitude of hippocampal PB potentiation and the level of serum corticosterone.

\section{METHOD}

Subjects were male Sprague-Dawley rats (Harlan Laboratories, Indianapolis, IN) weighing $275-420 \mathrm{~g}$ at the time of recording. The animals were group housed (2-3/cage) and given food and water ad lib. All animals had at least 1 week to acclimate to the vivarium 12:12-h light:dark cycle (lights on at 0600 ) before undergoing any surgical procedures. Adrenalectomy (ADX) was performed on secobarbital $(40 \mathrm{mg} / \mathrm{kg}$, i.p.) anesthetized rats $7-10$ days before the recordings took place. ADX subjects were maintained on rat chow and $0.9 \%$ saline available ad lib.

At $0900-1000$ on the day of recording, atropine methyl nitrate was administered $(0.2 \mathrm{mg} / \mathrm{kg}$, i.p.), followed by urethane (range: $1.1-1.5 \mathrm{~g} / \mathrm{kg}$, i.p.). Blood was obtained from the tail approximately 35 min after the induction of anesthesia; a second sample was obtained at the termination of the recording session, approximately $3.5 \mathrm{~h}$ later. The blood samples were analyzed for corticosterone by using a modification of radioimmunoassay (RIA) procedures (Keith, Winslow, \& Reynolds, 1978), which had an intra-assay coefficient of variation of $8.7 \%$. Serum corticosterone levels are stable when an animal is under urethane anesthesia (Spriggs \& Stockham, 1964). We used the mean value of the corticosterone samples obtained at the two time points in the correlation analysis between PB potentiation and corticosterone. The present work utilized a correction factor in the RIA analysis that provided a more accurate assessment of corticosterone levels than was reported in our earlier paper (Diamond et al., 1989). The corrected values from the previous work are a range of 34.6-82.1 $\mu \mathrm{g} / \mathrm{dl}(M=$ $65 \pm 17.8 \mu \mathrm{g} / \mathrm{dl}$ ) for serum corticosterone levels of the intact rats under urethane anesthesia.

When the subject was anesthetized, an incision was made and the tissue was bathed with a local anesthetic ( $0.4 \%$ Xylocaine). The recording electrode (etched epoxylite-insulated tungsten, impedance 0.5-1.0 MR at $1 \mathrm{kHz}$ ) was lowered to the CA1 pyramidal cell layer, which was identified by complex spike activity occurring
1.8-2.3 mm below brain surface. The stimulating electrode (125$\mu \mathrm{m}$-diameter stainless steel Teflon-coated wire, uninsulated at the tip) was lowered into the left side of the hippocampal commissure (coordinates AP - 1.8, ML 1.0). The final coordinates were determined by optimizing the amplitude of the population spike, which is a measure of synchronous firing of CA1 cell activity (Andersen, Bliss, \& Skrede, 1971).

Stimulus-evoked responses were displayed on an oscilloscope and stored in an Epson computer for on- and off-line analysis. Test responses were evoked by constant-current single-pulse stimuli (150$\mu \mathrm{sec}$ duration) presented every $30 \mathrm{sec}$ for $10 \mathrm{~min}$ before and $20 \mathrm{~min}$ following PB stimulation. PB stimulation consisted of a single pulse, followed $170 \mathrm{msec}$ later by a burst of 4 pulses at $200 \mathrm{~Hz}$. PB stimulation current levels were $150 \%$ of the current levels used in test pulses. Statistical analysis ( $t$ test) of the changes in the population spike amplitude was performed for each subject by comparing responses obtained during the 5-min period immediately prior to PB stimulation with those obtained during the 1- to 2-min (posttetanic potentiation, or PTP) and 16- to $20-\mathrm{min}$ (PB potentiation) periods after PB stimulation. Statistical comparisons across groups of animals were performed with a multivariate analysis of variance (MANOVA). Data are presented as the mean ( $\pm S E M$ ) unless otherwise noted. Additional details concerning the methodology are provided in Diamond et al. (1989).

\section{RESULTS}

Physiological recordings and serum corticosterone analyses were performed on 20 adrenal-intact (intact) and 12 adrenalectomized (ADX) subjects. The intact subjects had serum concentrations of corticosterone in the stress range $(25-93 \mu \mathrm{g} / \mathrm{dl}, M=53.4 \pm 4.1 \mu \mathrm{g} / \mathrm{dl})$. This finding is consistent with previous studies demonstrating that urethane anesthesia produces a chronic elevation of corticosterone levels (Dunn, 1987; Hamstra, Doray, \& Dunn, 1984; Spriggs \& Stockham, 1964) through the increased release of ACTH (Ondo \& Kitay, 1973). The mean corticosterone level in ADX subjects was $1.4 \mu \mathrm{g} / \mathrm{dl}( \pm 0.3)$. Levels of corticosterone in this low range are commonly measured in adrenalectomized rats, presumably from extra-adrenal tissue producing small quantities of corticosterone (Roy, Lynn, \& Bemm, 1990). The baseline stimulation current was $59.4 \mu \mathrm{A}( \pm 9.3)$ for the ADX group and $49.0 \mu \mathrm{A}$ $( \pm 4.9)$ for the intact group. The baseline population spike amplitude was $2.56 \mathrm{mV}( \pm 0.30)$ for the $\mathrm{ADX}$ group and $2.32 \mathrm{mV}( \pm 0.25)$ for the intact group. Neither the baseline stimulation current levels nor the baseline population spike amplitudes differed significantly between the two groups $(t=0.989, p>.05$, and $t=0.614, p>.05$, respectively).

There was a significant negative correlation between the magnitude of $\mathrm{PB}$ potentiation and level of serum corticosterone in intact animals $(r=-.76, p<.001$; see Figure 1). Intact subjects exhibited a significant increase $(n=9)$, no change $(n=7)$, or a decrease $(n=4)$ in the amplitude of the population spike in the $16-$ to $20-\mathrm{min}$ period following PB stimulation (paired $t$ test). The magnitudes of the evoked responses in this time period were significantly different across the three groups [increase, $82.5 \% \pm 12.1 \%$; no change, $1.7 \% \pm 11.0 \%$; decrease, $-42.8 \% \pm 10.9 \%$; repeated measures MANOVA, $F(2,17)$ 


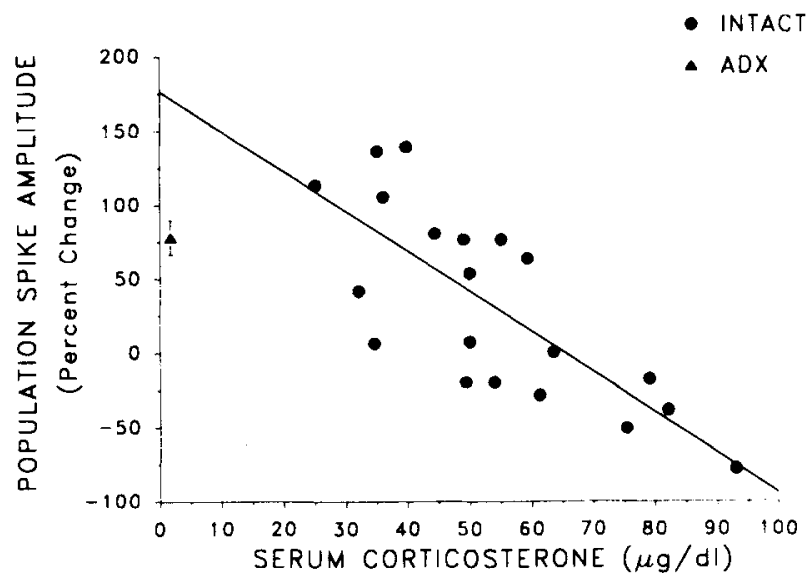

Figure 1. Signincant negative linear correlation between levels of corticosterone and the magnitude of primed burst (PB) potentiation and depression in intact subjects $(r=-.76, p<.001)$. The mean magnitude $( \pm S E M)$ of $\mathrm{PB}$ potentiation in ADX subjects ( $n$ $=12$ ) is indicated by the filled triangle.

$=27.18, p<.001]$. In post hoc analyses, the increase group was significantly different from the no-change group (Tukey-Kramer modification of $H S D, p<.01$ ) and the no-change group was significantly different from the decrease group (Tukey-Kramer modification of $H S D$, $p<.01)$.

In contrast with the intact subjects, which exhibited heterogeneous responses to PB stimulation, the ADX subjects all (12/12) exhibited PB potentiation, with a mean increase of $73.0 \%( \pm 11.8 \%)$ over baseline. The overall distribution of responses to PB stimulation (numbers of subjects exhibiting an increase:no change:decrease) for the intact group differed significantly from that of the ADX group [9:7:4 vs. 12:0:0, $\left.\chi^{2}(2)=10.1, p<.01\right]$. The mean magnitudes of $P B$ potentiation for these two groups also differed significantly. [All intact $=32.1 \%$ increase $( \pm 13.0 \%)$ vs. all $\mathrm{ADX}=73.0 \%$ increase $( \pm 11.8 \%), t=2.33, p<.05]$.

There was no significant relationship between the magnitude of PTP and the level of serum corticosterone $(r=.13, p>.1)$. All intact and ADX subjects exhibited an increase in the amplitude of the population spike in the 1- to 2-min period (PTP) following PB stimulation. The magnitudes of PTP across the three groups of animals (as defined above) were not significantly different: increase $=215.1 \% \pm 37.1 \%$; no change $=195.2 \% \pm 59.9 \%$; decrease $=176.8 \% \pm 59.2 \%$ [repeated measures MANOVA, $F(2,17)=0.13, p<.10]$. Hence, the characteristics of PTP did not serve as a reliable predictor of the characteristics of the evoked response in the 16- to 20-min period after PB stimulation. These findings are summarized in Figure 2. Examples of population spikes recorded before and after PB stimulation in intact animals with low (36$\mu \mathrm{g} / \mathrm{dl})$ and high $(75-\mu \mathrm{g} / \mathrm{dl})$ serum corticosterone are provided in Figure 3.

\section{DISCUSSION}

As in our previous work, both the incidence and the magnitude of $\mathrm{PB}$ potentiation were greater in adrenalectomized than in intact rats (Diamond et al., 1989). The present work extends our initial findings by describing a systematic relationship between $\mathrm{PB}$ potentiation and corticosterone. Specifically, there was a negative linear correlation between the magnitude of PB potentiation and the level of serum corticosterone. In addition, we have shown that serum corticosterone level is correlated with the magnitude of long-term, but not short-term, plasticity, and that PB stimulation induced a decrease in the amplitude of the population spike in animals with the highest levels of corticosterone measured.

\section{Possible Basis of the Negative Correlation Between Corticosterone and PB Potentiation}

Although corticosterone levels in the subjects of the present investigation were high, they were within the physiological range. Stress can elevate serum corticosterone levels to a range of approximately $20-80 \mu \mathrm{g} / \mathrm{dl}$ in rats (Muir \& Pfister, 1987; Overmier \& Murison, 1989; Shors et al., 1989). Moreover, the hippocampal corticosterone (Type II) receptor system does not become fully occupied until peripheral corticosterone levels are at least $100 \mu \mathrm{g} / \mathrm{dl}$ (de Kloet \& Reul, 1987). Therefore, the levels of corticosterone obtained in the subjects of the present study $(25-93 \mu \mathrm{g} / \mathrm{dl})$ were within the range of previously described behavioral stress-evoked responses and hippocampal receptor sensitivity.

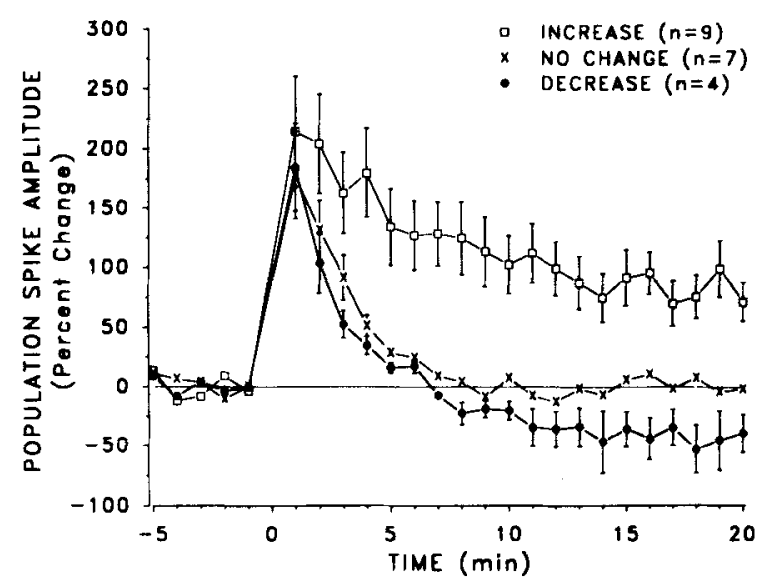

Figure 2. Heterogeneous long-term, but not short-term, responses produced by primed burst (PB) stimulation. PB stimulation was dellvered at Time $0(-5$ to $-1 \mathrm{~min}$ is boseline stimulation, and 1-20 $\mathrm{min}$ is the post-PB stimulation period). PB stimulation induced an increase in response in 9 animals (open square) and a decrease in response in 4 animils (filled circle). No significant change in response occurred in 7 animals (data points identified with an $x$ ). Data are expressed as the mean $( \pm S E)$ for $1-\mathrm{min}$ values. Error bars for most of the no-change group data points are within the size of the data points. 


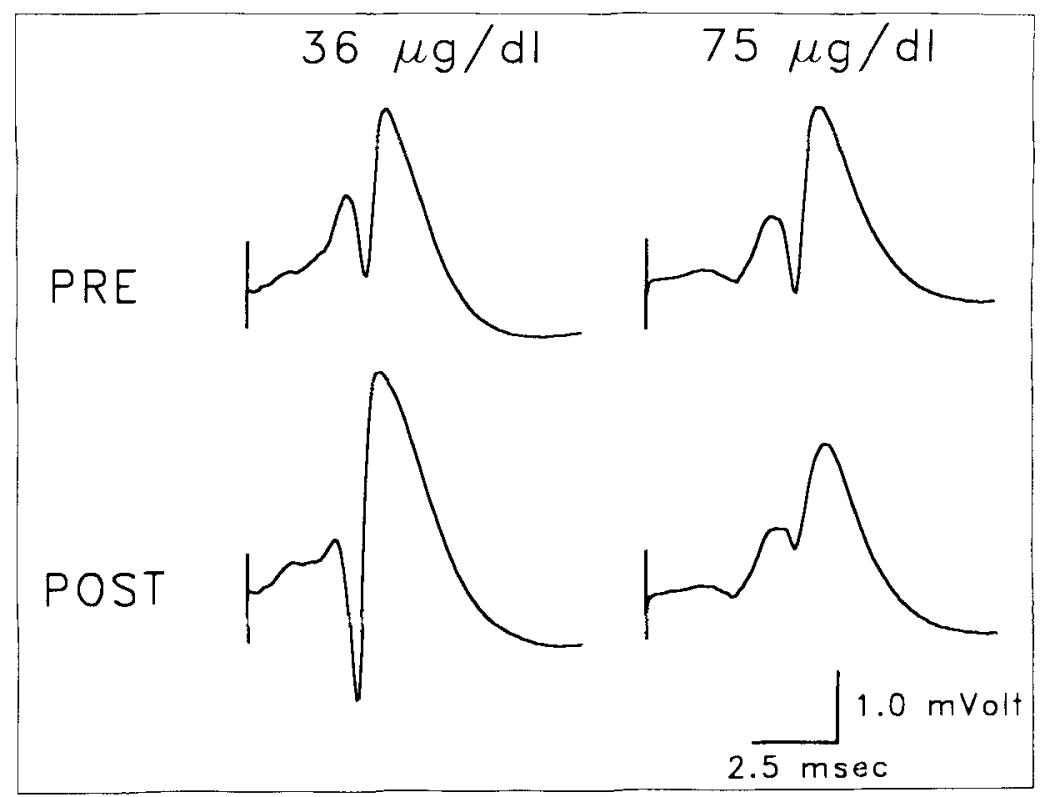

Figure 3. Examples of the effects of primed burst (PB) stimulation on population spike amplitudes in 2 subjects. In each case, the response at the top of the figure is the average of the responses recorded $5 \mathrm{~min}$ prior to PB stimulation, and the response at the bottom is the average recorded 16-20 min after PB stimulation. The response at the left is a 105\% increase in response obtained in a subject with a corticosterone level of $36 \mu \mathrm{g} / \mathrm{dl}$; the response at the right is a $51 \%$ decrease in response obtained in a subject with a corticosterone level of $75 \mu \mathrm{g} / \mathrm{dl}$.

Our finding of a negative correlation between stress levels of corticosterone and PB potentiation is consistent with recent work indicating that corticosterone can affect the excitability of hippocampal neurons through the activation of two types of receptors, referred to as Type I and Type II glucocorticoid receptors. The Type I receptor, which has a high affinity for corticosterone, is located primarily in the hippocampus, but the Type II receptor, which has a lower affinity for corticosterone, is widely distributed throughout the nervous system (Magariños et al., 1989; Reul, van den Bosch, \& de Kloet, 1987). Type I receptors become saturated at relatively low levels of corticosterone (less than $20 \mu \mathrm{g} / \mathrm{dl}$ ), but Type II receptors bind corticosterone in the range of approximately 20-100 $\mu \mathrm{g} / \mathrm{dl}$ (de Kloet \& Reul, 1987; Spencer, Young, Choo, \& McEwen, 1990). It is likely that Type I receptors were saturated in all of the recordings from adrenalintact rats in the present study, while there was a concentration-dependent occupation of the Type II receptors.

Activation of the Type II receptor by corticosterone increases the amplitude of a long-duration inhibitory potential, referred to as the afterhyperpolarization (AHP) (Joels \& de Kloet, 1989, 1990; Kerr et al., 1989). The priming pulse of PB stimulation produces an AHP (Storm, 1987). It is therefore likely that in recordings from rats with increased levels of corticosterone there was an increased magnitude of the AHP that may have damped the level of depolarization produced by the four-pulse burst (Davies, Starkey, Pozza, \& Collingridge, 1991; Pacelli, Su, $\&$ Kelso, 1989). This putative blockade of depolarization by corticosterone may have interfered with the NMDAmediated induction of PB potentiation (Diamond et al., 1988; Larson \& Lynch, 1988). We suggest that the basis of the negative correlation between corticosterone and PB potentiation is an increase in AHP amplitude produced by the concentration-dependent occupation of Type II receptors.

\section{PB Depression}

In $20 \%$ of the recordings, PB stimulation induced a significant decrease in the amplitude of the CA1 population spike. We refer to this decrease in response as PB depression. We considered the possibility that PB depression occurred as a result of seizure activity. However, we did not observe physiological indicators of seizure activity in any recordings. This finding is consistent with other work which shows that urethane anesthesia raises the threshold for the development of seizure activity (Cain, Raithby, \& Corcoran, 1989). Moreover, seizure activity would have been expected to produce an initial short-term depression of activity followed by either a return of the amplinde of the response to baseline levels or a potentiation of the response (Buzsaki, 1980; Staubli \& Lynch, 1987). Instead, recordings of PB depression showed an initial increase in response followed by a long-lasting 
decrease in response. Therefore, PB depression was not likely to have been produced as a result of seizure-related activity.

The characteristics of the PB depression described in this study are consistent with a mechanism of long-term depression (LTD) proposed by Artola, Brocher, and Singer (1990). Their work, in concert with similar findings of Stanton and Sejnowski's (1989), indicates that the depolarization threshold for LTD is lower than that for LTP. They also demonstrated that identical parameters of electrical stimulation can induce either LTD or LTP, depending on the level of postsynaptic depolarization at the time of high-frequency stimulation. Without exception, the subjects that exhibited PB depression had very high levels of serum corticosterone (greater than $60 \mu \mathrm{g} / \mathrm{dl}$ ). It is possible that the amplitude of the AHP associated with these high levels of corticosterone damped the burstinduced depolarization such that the threshold for PB depression, but not PB potentiation, was exceeded.

One approach toward a greater understanding of the mechanisms underlying PB depression is to administer selective Type II agonists and then deliver PB stimulation. We predict that there will be a negative relationship between the magnitude of $\mathrm{PB}$ potentiation and the concentration of a Type II agonist, such as dexamethasone. We would also expect that a negative correlation between dexamethasone and $\mathrm{PB}$ potentiation would produce PB depression at sufficiently high concentrations of dexamethasone.

\section{Discrepancy Between Predicted and \\ Empirically Determined Data}

The recordings in the present study were limited to relatively high serum corticosterone levels that corresponded to stress levels of corticosterone in the awake animal. The shape of the corticosterone/PB potentiation function for corticosterone levels below $25 \mu \mathrm{g} / \mathrm{dl}$ remains to be determined. An extrapolation of the linear regression shown in Figure 1 predicts that the amplitude of PB potentiation would be approximately a $175 \%$ increase in response at the trace levels of corticosterone found in the ADX subjects. Instead, we found an increase of only $73 \%$ in the ADX subjects. Moreover, there was no overlap between the mean and the standard error of PB potentiation for the ADX group and the $95 \%$ confidence limits of the regression line at the $y$ intercept.

One possible explanation for the discrepancy is that corticosterone produces an inverted-U-shaped modulation of hippocampal plasticity. According to this hypothesis, PB potentiation reaches a peak magnitude at an intermediate level of corticosterone (e.g., 10-20 $\mu \mathrm{g} / \mathrm{dl}$ ) and then declines as corticosterone levels approach $0 \mu \mathrm{g} / \mathrm{dl}$. An inverted- $U$ relationship between an adrenal hormone and hippocampal plasticity has been described previously by Gold et al. (1984). These investigators demonstrated that there is an inverted-U relationship between the dose of peripherally administered epinephrine and the magnitude of hippocampal LTP in anesthetized rats. Inverted-U relationships between stress hormones and hippocampal plasticity may underlie the well-described inverted- $U$ modulation of learning by arousal (Broadbent, 1971; Broadhurst, 1959; Lundberg, 1982; Yerkes \& Dodson, 1908).

An alternative hypothesis is that the discrepancy is the result of ADX-induced sequelae (see, e.g., de Kloet, Sybesma, \& Reul, 1986; Miller, Greenblatt, Barnhill, Thompson, \& Shaderh, 1988; Swann, 1988). This hypothesis predicts that intact animals with low levels of corticosterone (1-2 $\mu \mathrm{g} / \mathrm{dl})$ will have a PB potentiation magnitude of approximately $175 \%$ (the linear regression $y$ intercept value). If this does occur, the discrepancy between the expected and observed values in the present study would appear to be a result of an adrenalectomyinduced uncoupling of the hormonal modulation of hippocampal plasticity.

Our initial studies to distinguish between these two alternatives support the inverted-U hypothesis. In animals that have experimenter-determined levels of corticosterone (by means of adrenalectomy and the implantation of corticosterone pellets), the corticosterone/PB potentiation curve reaches a peak PB potentiation magnitude at approximately $9-20 \mu \mathrm{g} / \mathrm{dl}$, with a reduction in the magnitude of $\mathrm{PB}$ potentiation in animals with lower and higher levels of corticosterone (Diamond, Bennett, Meltzer, Fleshner, \& Rose, 1991).

\section{Relation to Previous Studies}

The negative correlation between corticosterone and PB potentiation does not appear to be produced as an artifact of the urethane anesthesia, nor is it induced only by primed burst stimulation. A similar negative correlation between hippocampal plasticity and corticosterone was reported by Foy et al. (1987), whose methodology differed considerably from that in the present work. Foy et al. applied a high-frequency train of 100 pulses to the hippocampal slice obtained from unanesthetized, stressed rats. In contrast, we applied a total of 5 physiologically patterned pulses to the intact hippocampus of urethane-anesthetized rats. Hence, the correlation between hippocampal longterm plasticity and corticosterone appears to be a robust phenomenon that is expressed (1) in response to physiologically patterned stimulation or more conventional LTP stimulation, (2) in the presence or absence of anesthesia, and (3) in CAl of either the intact hippocampus in vivo or the hippocampus in vitro.

The similarity between our observations of the modulation of hippocampal plasticity and those of Foy et al. (1987) parallels observations of the effects of stress on long-term plasticity in unanesthetized rats. We have shown that stress interferes with the development of PB potentiation in behaving rats (Diamond et al., 1990). Similarly, Thompson and his colleagues have demonstrated that stress blocks the induction of LTP (Foy et al., 1987; Shors et al., 1989). However, there is less consistency in the effects of stress on short-term plasticity. We have shown that stress completely blocked the induction of PTP in recordings from behaving rats (Diamond et al., 1990). 
In contrast, Shors et al. (1989) observed an attenuation of PTP by stress, whereas in other work from their laboratory there was no effect of stress on PTP (Foy et al., 1987; Shors, Levine, \& Thompson, 1990).

In the present study, PTP occurred in all animals, independently of corticosterone level. These contrasts between stress and corticosterone effects on PTP and LTP are consistent with the hypothesis that long- and shortterm forms of plasticity are induced by different mechanisms (McNaughton, 1982). They also indicate that stress in the behaving animal can produce a potent blockade on short- and long-term forms of plasticity, but a pharmacologically induced increase in corticosterone, as described here, is associated only with the suppression of long-term plasticity. The finding that serum corticosterone in the anesthetized rat does not affect PTP is consistent with the evidence that substances other than corticosterone, such as opioids (Shors, Levin, \& Thompson, 1990), contribute to stress effects on hippocampal plasticity.

\section{Summary}

We have demonstrated that there is an inverse relationship between levels of corticosterone and the magnitude of PB potentiation. Although these data are correlative, they are consistent with the possibility of a direct modulation of hippocampal plasticity by corticosterone. The additional finding of a discrepancy between the predicted and observed magnitudes of $\mathrm{PB}$ potentiation for the ADX subjects raises the question of the relationship between corticosterone and PB potentiation at lower levels of corticosterone. Finally, in a subset of recordings in animals with the highest levels of corticosterone, PB stimulation induced a depression of the amplitude of the population spike. We suggest that the basis of the negative correlation between corticosterone and $\mathrm{PB}$ potentiation, as well as the induction of PB depression, is the concentrationdependent occupation of corticosterone Type II receptors.

\section{REFERENCES}

Andersen, P., Bliss, T. V. P., Skrede, K. (1971). Unit analysis of hippocampal population spikes. Experimental Brain Research, 13, 208-221.

Archer, T., Ogren, S. O., Fuxe, K., Agnati, L. F., \& Eneroth, P. (1981). On the interactive role of central noradrenaline neurons and corticosterone in two-way active avoidance acquisition in the rat. Neuroscience Letters, 27, 341-346.

Artola, A., Brocher, S., \&inger, W. (1990). Different voltagedependent thresholds for inducing long-term depression and long-term potentiation in slices of rat visual cortex. Science, 347, 69-72.

Bennett, C., Liang, K. C. \& MCGaugh, J. L. (1985). Depletion of adrenal catecholamines alters the amnestic effect of amygdala stimulation. Behavioural Brain Research, 15, 83-91.

BoHUs, B. (1973). Pituitary-adrenal influences on avoidance and approach behavior of the rat. In E. Zimmerman, W. H. Gispen, \& D. De Wied (Eds.), Progress in brain research: Drug effects on neuroendocrine regulation (pp. 407-420). Amsterdam: Elsevier.

BohUS, B., DE KLOET, E. R. (1981). Adrenal steroids and extinction behavior: Antagonism by progesterone, deoxycorticosterone and dexamethasone of a specific effect of corticosterone. Life Sciences, 28 , 433-440.
Bohus, B., Grubits, J., Kovacs, G., Lissax, K. (1970). Effects of corticosteroids on passive avoidance behavior of rats. Academia Scientiarum Hungarica: Acta Physiologica, 37, 265-272.

Borrell, J., de KLOET, E. R., Versteeg, D. H., B BohUs, B. (1983). Inhibitory avoidance deficit following short-term adrenalectomy in the rat: The role of adrenal catecholamines. Behavioral \& Neural Biology, 39, 241-258.

Brondbent, D. E. (1971). Decision and stress. London: Academic Press.

Brondhurst, P. L. (1959). The interaction of task difficulty and motivation. The Yerkes-Dodson law revisited. Acta Psychologica, 16, 321-338.

BuZsAKI, G. (1980). Long-term potentiation of the commissural pathCA1 pyramidal cell synapse in the hippocampus of the freely moving rat. Neuroscience Letters, 19, 293-296.

Cain, D. P., Raithby, A., CorCoran, M. E. (1989). Urethane anesthesia blocks the development and expression of kindled seizures. Life Sciences, 44, 1201-1206.

Davies, C. H., Starkey, S. J., Pozza, M. F., \& Collingridge, G. L. (1991). GABA $A_{B}$ autoreceptors regulate the induction of LTP. Nature, 349, 609-611.

DE KLOET, E. R., \& ReUL, J. M. H. M. (1987). Feedback action and tonic influence of corticosteroids on brain function: A concept arising from the heterogeneity of brain receptor systems. Psychoneuroendocrinology, 12, 83-105.

De Kloet, E. R., Sybesma, H., \& Reul, J. M. H. M. (1986). Selective control by corticosterone of serotonin1 receptor capacity in raphehippocampal system. Neuroendocrinology, 42, 513-521.

Diamond, D. M., Bennett, M. C., Engstrom, D. A., Fueshner, M., a Rose, G. M. (1989). Adrenalectomy reduces the threshold for hippocampal primed burst potentiation in the anesthetized rat. Brain Research, 492, 356-360.

Diamond, D. M., Bennett, M. C., Meltzer, J., Fleshner, M., \& Rose, G. M. (1991). Inverted-U relationship between corticosterone and hippocampal primed burst potentiation in urethane-treated rats. Society for Neuroscience Abstracts, 17, 387.

Diamond, D. M., BennetT, M. C., Stevens, K. E., Wilson, R. L., * Rose, G. M. (1990). Exposure to a novel environment interferes with the induction of hippocampal primed burst potentiation in the behaving rat. Psychobiology, 18, 273-281.

Diamond, D. M., Dunwiddie, T. V., Rose, G. M. (1988). Characteristics of hippocampal primed burst potentiation in vitro and in the awake rat. Joumal of Neuroscience, 8, 4079-4088.

Dubrovsky, B. O., Liquornik, M. S., Noble, P., Gusbers, K. (1987). Effects of 5-alpha-dihydrocorticosterone on evoked responses and long-term potentiation. Brain Research Bulletin, 19, 635-638.

DunN, J. D. (1987). Differential plasma corticosterone responses to electrical stimulation of the medial and lateral septal nuclei. Neuroendocrinology, 46, 406-411.

Foy, M. R., Stanton, M. E., Levine, S., \& Thompson, R. F. (1987). Behavioral stress impairs long-term potentiation in rodent hippocampus. Behavioral \& Neural Biology, 48, 138-149.

Gold, P. E., Delanoy, R. L., Merrin, J. (1984). Modulation of long-term potentiation by peripherally administered amphetamine and epinephrine. Brain Research, 305, 103-107.

Greenstein, Y. J., PAvlides, C., \& Winson, J. (1988). Long-term potentiation in the dentate gyrus in preferentially induced at theta rhythm periodicity. Brain Research, 438, 331-334.

Hamstra, W. N., Doray, D., \& DunN, J. D. (1984). The effect of urethane on pituitary-adrenal function of female rats. Acta Endocrinologica, 106, 362-367.

JOELS, M., DE KLOET, E. R. (1989). Effects of glucocorticoids and norepinephrine on the excitability in the hippocampus. Science, 245 , 1502-1505.

Jozls, M., \& DE Kloet, E. R. (1990). Mineralocorticoid receptormediated changes in membrane properties of rat CAl pyramidal neurons in vitro. Proceedings of the National Academy of Sciences (U.S.A.), 87, 4495-4498.

KeIth, L. D., WinsLow, J. R., Reynolds, R. W. (1978). A general procedure for estimation of corticosteroid response in individual rats. Steroids, 31, 523-531. 
Kerr, D. S., Campeell, L. W., Hao, S.-Y., Landfield, P. W (1989). Corticosteroid modulation of hippocampal potentials: Increased effect with aging. Science, 245, 1505-1509.

LARSON, J., \& LYNCH, G. (1986). Induction of synaptic potentiation in hippocampus by patterned stimulation involves two events. Science, 232, 985-988.

LARSON, J., LYNCH, G. (1988). Role of N-methyl-D-aspartate receptors in the induction of synaptic potentiation by burst stimulation patterned after the hippocampal theta-rhythm. Brain Research, 441, 111-118.

Larson, J., Wong, D., \& Lynch, G. (1986). Patterned stimulation at the theta frequency is optimal for the induction of hippocampal longterm potentiation. Brain Research, 368, 347-350.

Liang, K. C., Bennett, C., \&cGaugh, J. L. (1985). Peripheral epinephrine modulates the effects of post-training amygdala stimulation on memory. Behavioural Brain Research, 15, 93-100.

LUNDBERG, U. (1982). Psychophysiological aspects of performance and adjustment to stress. In H. W. Krohne \& L. Laux (Eds.), Achievement, stress, and anxiety (pp. 75-92). New York: Hemisphere.

Lynch, G., Muller, D., Seubert, P., \& Larson, J. (1988). Longterm potentiation: Persisting problems and recent results. Brain Research Bulletin, 21, 363-372.

Magariños, A. M., Ferrini, M., \& De Nicola, A. F. (1989). Corticosteroid receptors and glucocorticoid content in microdissected brain regions: Correlative aspects. Neuroendocrinology, 50, 673-678.

MCGAUGH, J. L. (1989). Involvement of hormonal and neuromodulatory systems in the regulation of memory storage. Annual Review of Neuroscience, 12, 255-287.

MCNaughton, B. L. (1982). Long-term synaptic enhancement and short-term potentiation in rat fascia dentata act through different mechanisms. Journal of Physiology, 324, 249-262.

Miller, L. G., Greenblatt, D. J., Barnhill, J. G., Thompson, M. L., ShaDERH, R. I. (1988). Modulation of benzodiazepine receptor binding in mouse brain by adrenalectomy and steroid replacement. Brain Research, 446, 314-320.

Muir, J. L., \& Pfister, H. P. (1987). Time course of the corticosterone and prolactin response following predictable and unpredictable novelty stress in Rattus norvegicus. Physiology \& Behavior, 40 , 103-107.

ONDO, J. G., \& KJTAY, J. I. (1973). Effects of urethane on pituitaryadrenal function in the rat. Proceedings of the Sociery for Experimental Biology \& Medicine, 143, 894-898.

Overmier, J. B., \& Murison, R. (1989). Poststress effects of danger and safety signals on gastric ulceration in rats. Behavioral Neuroscience, 103, 1296-1301.

Pacell, G. J., Su, W., Kelso, S. R. (1989). Activity-induced depression of synaptic inhibition during LTP-inducing patterned stimulation. Brain Research, 486, 26-32.

Pavlides, C., Greenstein, Y. J., Grudman, M. W Winson, J. (1988). Long-term potentiation in the dentate gyrus is induced preferentially on the positive phase of theta-rhythm. Brain Research, 439, 383-387.

Pfaff, D. W., Silva, M. T. A., \& Weiss, J. M. (1971). Telemetered recording of hormone effects on hippocampal neurons. Science, 172, 394-395
Reiheld, C. T., Teyler, T. J., \& Vardaris, R. M. (1984). Effects of corticosterone on the electrophysiology of hippocampal CA1 pyramidal cells in vitro. Brain Research Bulletin, 12, 349-353

Reul, J. M. H. M., DE KLOET, E. R. (1985). Two receptor systems for corticosterone in rat brain: Microdistribution and differential occupation. Endocrinology, 117, 2505-2511.

ReUl, J. M. H. M., VAN DEN Bosch, F. R., \& KL KLet, E. R. (1987). Relative occupation of type-I and type-II corticosteroid receptors in rat brain following stress and dexamethasone treatment: Functional implications. Joumal of Endocrinology, 115, 459-467.

Rose, G. M., DUNwIDDIE, T. V. (1986). Induction of hippocampal long-term potentiation using physiologically patterned stimulation. Neuroscience Letters, 69, 244-248.

Roy, E. J., LyNN, D. M., \& BemM, C. W. (1990). Individual variations in hippocampal dentate degeneration following adrenalectomy. Behavioral \& Neural Biology, 54, 330-336.

Shors, T. J., LeVINE, S. * ThOMPson, R. F. (1990). Opioid antagonist eliminates the stress-induced impairment of long-term potentiation (LTP). Brain Research, 506, 316-318.

Shors, T. J., Seib, T. B., LeVine, S., Thompson, R. F. (1989). Inescapable versus escapable shock modulates long-term potentiation in the rat hippocampus. Science, 244, 224-226.

SPENCER, R. L., Young, E. A., ChOO, P. H., MCEWen, B. S. (1990). Adrenal steroid type I and type II receptor binding: Estimates of in vivo receptor number, occupancy, and activation with varying levels of steroid. Brain Research, 514, 37-48.

SpricGs, T. L. B., StockHAM, M. A. (1964). Urethane anaesthesia and pituitary-adrenal function in the rat. Joumal of Pharmacy \& Pharmacology, 16, 603-610.

SQUTRE, L. R. (1986). Mechanisms of memory. Science, 232, 1612-1619.

Stanton, P. K., \& SEjnowski, T. J. (1989). Associative long-term depression in the hippocampus induced by Hebbian covariance. $\mathrm{Na}$. ture, 339, 215-218.

SAUBL, U., \& LYNCH, G. (1987). Stable hippocampal long-term potentiation elicited by "theta" pattern stimulation. Brain Research, 435 227-234.

STORM, J. F. (1987). Action potential repolarization and a fast afterpolarization in rat hippocampal pyramidal cells. Joumal of Physiology, 385, 733-750.

SwanN, A. C. (1988). Dexamethasone and adrenalectomy alter brain $\left(\mathrm{Na}^{+}, \mathrm{K}^{+}\right)$-ATPase responses to noradrenergic stimulation or depletion. European Journal of Pharmacology, 158, 43-52.

Teyler, T. J., DiScenna, P. (1987). Long-term potentiation. Annual Review of Neuroscience, 10, 131-161.

YERKES, R. M., \& DoDsON, J. D. (1908). The relation of strength of stimulus to rapidity of habit-formation. Journal of Comparative Neurology \& Psychology, 18, 459-482.

Zola-Morgan, S., Squire, L. R., \& Amaral, D. G. (1986). Human amnesia and the medial temporal region: Enduring memory impairment following a bilateral lesion limited to field $\mathrm{CA} 1$ of the hippocampus. Journal of Neuroscience, 6, 2950-2967.

(Manuscript received February 28, 1991; revision accepted for publication June 28,1991 .) 